\title{
O PAPEL DOS CONSELHOS DE ACOMPANHAMENTO E CONTROLE SOCIAL NOS PLANOS ESTADUAIS DE EDUCAÇÃO ALINHADOS AO PNE 2014-2024
}

\author{
Donaldo Bello de Souza ${ }^{1}$
}

\section{RESUMO}

Considerando a importância dos Conselhos de Acompanhamento e Controle Social (CACS) tanto para os processos de construção nacional e local da gestão democrática, quanto para a consolidação dos modos de acompanhamento e controle social dos recursos públicos destinados à educação, este artigo visa à análise do seu papel nos Planos Estaduais de Educação (PEEs) alinhados ao PNE 2014-2024, com foco nos Conselhos do Fundo de Manutenção e Desenvolvimento da Educação Básica e de Valorização dos Profissionais da Educação (FUNDEB) e do Programa Nacional de Alimentação Escolar (PNAE). Evidencia reduzido valor institucional e sociopolítico desses órgãos no âmbito dos sistemas de ensino e, em particular, na esfera do planejamento estadual da educação, quer em função do formalismo e/ou superficialidade refletidos no conjunto das estratégias identificadas nesses PEEs, quer, de forma ainda mais crítica, em decorrência de sucessivas omissões a estes órgãos colegiados, absenteísmos que se estendem a partir da definição do seu papel, passando pela caracterização dos espaços de sua atuação, culminando na explicitação do necessário apoio financeiro e logístico aos mesmos.

Palavras-chave: Conselhos de Acompanhamento e Controle Social; Planos Estaduais de Educação; FUNDEB; PNAE.

\section{THE ROLE OF MONITORING AND SOCIAL CONTROL COUNCIL IN STATE EDUCATIONAL PLANS ALIGNED TO PNE 2014-2024}

\begin{abstract}
Considering the importance of the Monitoring and Social Control Council (CACS) for both the national construction process and local democratic management, and for the consolidation of the monitoring modes and social control of public resources for education, this article aims to analysis of their role in the State Education Plans (PEEs) aligneds to the PNE 2014-2024, focusing on the Councils of the Fund for the Development of Basic Education and Valuing of Education Professionals (FUNDEB) and the National School Feeding Program (PNAE). Shows reduced institutional and socio-political value of these organisms within the education systems and, in particular, in the sphere of state planning of education, whether due to the formalism and / or reflected superficiality in all the identified strategies in these PEEs either, even form more critical as a result of successive omissions these collegiate bodies, absenteeism that extend from the definition of its role, through the characterization of areas of its activities, culminating in the clarification of the necessary financial and logistical support to these collegiate bodies.
\end{abstract}

Keywords: Monitoring Boards and Social Control; State Education Plans; FUNDEB; PNAE. 


\section{INTRODUÇÃO}

$\mathrm{Na}$ segunda metade dos anos 1980, a redemocratização do Brasil, cujo marco jurídico fundamental consiste na promulgação da Constituição Federal (CF) de 1988 (BRASIL, 1988), irá favorecer a recuperação das bases do Estado federativo brasileiro (eleições diretas e descentralização fiscal), também inaugurando tendências relacionadas à descentralização das políticas sociais (ARRETCHE, 2002; 1999).

A partir deste novo contexto constitucional, a partilha de poderes entre o governo central e regional/local, assim como entre poder público e sociedade civil, passará a ser defendida, sob perspectiva descentralizadora, como ação de emancipação e empoderamento, entre outros, dos municípios e da comunidade local. Distanciar-se-ia, portanto, de um simples deslocamento de competências, atribuições e encargos, desvestido de poder político-decisório, como no caso da desconcentração (LAUGLO, 1996; CASSASUS, 1995), embora se mostrando dependente do contexto histórico e sociopolítico de cada realidade, definidor, em última instância, do grau e amplitude da descentralização (KRAWCZYK; VIEIRA, 2008; VENEZIANO, 2002; PÉRES; ROITH; SÂNCHEZ, 2000).

Contudo, na prática, a gestão e o financiamento das políticas sociais no Brasil passaram a se mover tipicamente de forma centralizada na esfera do governo federal (ARRETCHE, 2002), com elevado controle deste nível superior de governo sobre os fluxos financeiros e as transferências de recursos intergovernamentais (KUGELMAS; SOLA, 1999; GONÇALVES, 1998), visivelmente ancorado na manutenção da centralização normativa e política em relação à instância executora dos seus programas e projetos (COSTA; CUNHA; ARAÚJO, 2010; VIEIRA; FARIAS, 2007; MONTAÑO, 2003). Em muitos casos, as medidas ditas descentralizadoras acabaram por refletir processos de privatização, terceirização ou publicização dos serviços públicos (PERONI, 2003), com forte apelo às práticas sociais voluntárias, de caráter tipicamente assistencial (CALDERÓN; MARIM, 2003).

É neste cenário que, ao longo dos idos de 1990, se observou a estruturação de novas redes associativas (GOHN, 2001; 1998) e de canais de participação popular na esfera da gestão pública (LUCHMANN, 2007; MENDES, 2007; LAVALLE; HOUTZAGER; CASTELLO, 2006), com desenho institucional deliberativo (CUNHA; THEODORO, 2014; GURGEL; JUSTEN, 2013; OLIVEIRA; PEREIRA; OLIVEIRA, 2010), dentre os quais a criação de Conselhos nas diversas áreas das políticas públicas. Esses Conselhos viriam a ser amparados por ampla base legal, assumindo diversos formatos e funções, sendo caracteristicamente compostos por representantes do poder público e da sociedade civil, a exemplo das iniciativas em torno da criação dos Conselhos de Direitos, de Assistência Social, de Saúde, de Educação, entre outros (GOHN, 2001).

No campo da Educação Básica, em meio aos desafios postos pela Lei de Diretrizes e Bases da Educação Nacional (LDBEN) n 9.394, de 20 de dezembro de 1996 (BRASIL, 1996) à implantação da gestão democrática no âmbito dos sistemas locais de educação, disseminam-se os Conselhos Escolares, os Conselhos de Classe e de Série, os Grêmios Estudantis, os Conselhos Municipais de Educação (CMEs) e, especialmente, os Conselhos de Acompanhamento e Controle Social (CACS) (SOUZA, 2013a; 2008; 2006a; VALLE; VASCONELOS, 2012; MARTINS, A. 2011; OLIVEIRA et al., 2006; SCHEINVAR; ALGEBAILE, 2005).

Na esfera do planejamento nacional da educação, os CACS irão fazer-se presente, inicialmente, no Plano Nacional de Educação (PNE) 2001-2010 - Lei no 10.172, de 09 de janeiro de 2001 (BRASIL, 2001a) - e, quatro anos após o término de sua vigência, no PNE 2014-2024 - Lei $\mathrm{n}^{\mathrm{o}}$ 13.005, de 25 de junho de 2014 (BRASIL, 2014) -, isto com papel 
associado à consolidação da gestão democrática e à transparência da gestão e do financiamento da educação nas esferas federal, estadual, do Distrito Federal e municipal, com participação da sociedade civil, conforme mais adiante examinado. Ao nível do planejamento infranacional, há de se esperar que esses Conselhos também despontem em diretrizes relacionadas à democratização da gestão educacional, igualmente assumindo relevo no acompanhamento e controle social das políticas públicas locais de educação, já que, conforme determinado na lei que regulamenta o PNE 2014-2024, "Os Estados, o Distrito Federal e os Municípios deverão elaborar seus correspondentes planos de educação, ou adequar os planos já aprovados em lei, em consonância com as diretrizes, metas e estratégias previstas neste PNE" (BRASIL, 2014, art. $8^{\circ}$ ), agora no prazo de um ano contado a partir da publicação desta lei, ou seja, até fins de junho de 2015.

Considerando a importância dos CACS tanto para os processos de construção nacional e local da gestão democrática, quanto para a consolidação dos modos de acompanhamento e controle social dos recursos públicos destinados à educação, este artigo visa à análise do seu papel nos Planos Estaduais de Educação (PEEs) elaborados ou adequados em consonância ao PNE 2014-2024 (BRASIL, 2014), com foco nos Conselhos do Fundo de Manutenção e Desenvolvimento da Educação Básica e de Valorização dos Profissionais da Educação (FUNDEB) e do Programa Nacional de Alimentação Escolar (PNAE), únicos conselhos do gênero de competência direta nos sistemas de ensino no País.

Trata-se de um estudo de caráter exploratório e descritivo (KETELE; ROEGIERS, 1993), apoiado na análise de conteúdo (BARDIN, 2004) de fontes documentais primárias (LAVILLE; DIONNE, 1999) relativas aos PEEs do País - planos propriamente ditos e suas leis de criação -, que tenham sido efetivamente transformados em norma jurídica, ou seja, aprovados pelo legislativo, sancionados pelo executivo e, ainda, publicados em órgão oficial do estado correspondente, como, por exemplo, o Diário Oficial (DO). Do ponto de vista do campo das pesquisas em políticas de educação, este estudo concentra-se na ação pública (policy), nestes termos, tomando por objeto de análise, em exclusivo, o conteúdo das decisões políticas relacionadas ao planejamento decenal da educação estadual, embora reconhecendo a importância do exame sobre a ordem e estrutura dos sistemas políticoadministrativos (polity), a par do valor da compreensão acerca das relações de poder e formas de mobilização social que subjazem a esses mesmos conteúdos de ação pública (politics) (FREY, 2000; MULLER; SUREL, 1998), mas que fogem ao escopo do trabalho.

Assim, além desta seção introdutória, o artigo está composto por outras cinco partes, a começar pela descrição da situação atual dos PEEs no País, seguida da caracterização do FUNDEB e, após, do PNAE, também enfocando o funcionamento institucional e sociopolítico dos seus respectivos CACS. Já a quinta seção expõe a análise do papel desses Conselhos no âmbito dos PEEs considerados, examinando-os, em especial, a partir das respectivas metas de gestão democrática da educação e de financiamento, também observando sua eventual presença em outras decisões desses planos. Na sequencia, finalizase o estudo estabelecendo suas conclusões.

\section{O PEEs EM VIGÊNCIA}

Até fins de julho de 2016, apenas dois (8\%) dos 26 estados brasileiros não possuíam PEEs transformados em norma jurídica, ou seja, ainda não dispunham de planos que tivessem sido aprovados pelo legislativo, sancionados pelo executivo e, ainda, publicados em órgão oficial do estado correspondente ${ }^{2}$, ambos da Região Sudeste, a saber, Minas Gerais e Rio de Janeiro. De acordo com dados constantes da página do Ministério da Educação (MEC) ${ }^{3}$, o estado de Minas Gerais ainda se encontrava com o seu plano em 
trâmite na Assembléia Legislativa, enquanto que o Rio de Janeiro possuía, unicamente, o documento base do plano elaborado ${ }^{4}$.

Cabe ainda destacar que o plano do estado do Mato Grosso possui apenas 17 metas publicadas no seu Diário Oficial (DO) (MATO GROSSO, 2014), omitindo, com isto, as Metas 18, 19 e 20 do PNE 2014-2024 (BRASIL, 2014) relacionadas, respectivamente, aos planos de carreira dos profissionais da educação, à efetivação da gestão democrática e, ainda, à ampliação do investimento público em educação, expondo, em consequencia, nítido desalinhamento em relação a este novo plano nacional. Já os PEEs do Amazonas e Rondônia vieram a ter as suas leis publicadas nos respectivos DOs, mas desacompanhadas do texto do plano, cuja edição eletrônica é possível de se encontrar como documento avulso, apenas apensado à versão eletrônica do órgão oficial do estado (AMAZONAS, 2015; RONDÔNIA, 2015) $)^{5}$.

No que concerne ao conjunto de PEEs transformados em norma jurídica, cujo enquadramento legal encontra-se indicado no Quadro 1, sobressai um primeiro grupo de três (12\%) estados, composto pelo Maranhão, Mato Grosso e Mato Grosso do Sul, que veio a ter os seus respectivos PEEs aprovados em curto espaço tempo em relação à aprovação do PNE 2014-2024, os dois primeiros, inclusive, alguns dias antes da aprovação deste plano nacional, que ocorreu em 25 junho de 2014, enquanto que o terceiro seis meses após. No caso dos dois primeiros PEEs, tal aspecto põe em dúvida a sua elaboração, no sentido de terem resultado de discussões e deliberações pautadas no texto efetivamente aprovado deste novo PNE, envolvendo "ampla participação de representantes da comunidade educacional e da sociedade civil", conforme determinado no § 20 da Lei $n^{\circ} 13.005 / 2014$ (BRASIL, 2014). Além disto, sugerem portar desalinhamentos também em relação a este novo PNE, na medida em que podem não ter contemplado, em efetivo, o conteúdo de suas metas e estratégias, tendo-se pautado em algumas das versões que transitaram no Congresso Nacional. Por exemplo, no PEE do Maranhão (2014) é explicitado que as "metas e estratégias estabelecidas estão em consonância com as do Plano Nacional de Educação (2010-2020) num regime de colaboração mútua [...]", numa clara referência não ao PNE 2014-2014 (BRASIL, 2014) aprovado, mas, possivelmente, a alguma das versões preliminares deste plano nacional, derivadas do Projeto de Lei (PL) $\mathrm{n}^{\circ}$ 8.035, de 20 de dezembro de 2010 (BRASIL, 2011).

Um segundo agrupamento de nove (38\%) estados - Amapá, Amazonas, Espírito Santo, Pará, Paraíba, Paraná, Pernambuco, Rio Grande do Sul e Rondônia - veio a ter os seus planos aprovados ao final do mês de junho de 2015, notadamente dentro do prazo previsto na Lei $\mathrm{n}^{\mathbf{0}} 13005 / 2014$, qual seja, de um ano contado a partir de sua publicação (BRASIL, 2014, art. $8^{\circ}$ ). Ainda em 2015, destaca-se outro conjunto de sete (29\%) estados, composto pelos PEEs do Acre, Goiás e Tocantins, com menos de um mês de atraso; de Roraima e Sergipe, com quase três meses; enquanto que Santa Catarina e Piauí expondo, aproximadamente, seis meses de retardo.

Os demais cinco $(21 \%)$ estados vieram a ter os seus planos transformados em norma jurídica apenas a partir do início de 2016, a saber, Alagoas, Rio Grande do Norte, Bahia, Ceará e São Paulo, os dois primeiros com atraso de sete meses, os dois seguintes com 11 meses, enquanto que o quinto estado com mais de um ano relativo ao prazo legal, denotando desalinhamentos temporais expressivos em relação àquele novo plano nacional. 


\section{Quadro 1}

Enquadramento legal dos PEEs alinhados ao PNE 2014-2024 - jul. 2016

\begin{tabular}{|c|c|c|}
\hline REFERÊNCIA PEE & LEI N $^{\circ}$ & $\begin{array}{l}\text { PERÍODO DE } \\
\text { VIGÊNCIA }\end{array}$ \\
\hline Acre & 2.965 de 2 de julho de 2015 & $2015-2024$ \\
\hline Alagoas & 7.795 de 22 de janeiro de 2016 & $2016-2026^{(*)}$ \\
\hline Amapá & 1.907 de 24 de junho de 2015 & $2015-2025$ \\
\hline Amazonas & 4.183 de 26 de junho de 2015 & $2015-2025^{(*)}$ \\
\hline Bahia & 13.559 de 11 de maio de 2016 & $2016-2026^{(*)}$ \\
\hline Ceará & 16.025 de 30 de maio de 2016 & 2016-2024 \\
\hline Espírito Santo & 10.382 de 24 de junho de 2015 & $2015-2025$ \\
\hline Goiás & 18.969 de 22 de julho de 2015 & $2015-2025$ \\
\hline Maranhão & 10.099 de 11 de junho de 2014 & $2014-{ }^{(* *)}$ \\
\hline Mato Grosso & 10.111 de 06 de junho de 2014 & $2014-^{(* *)}$ \\
\hline Mato Grosso do Sul & 4.621 de 22 de dezembro de 2014 & $2014-2024^{(*)}$ \\
\hline Pará & 8.186 de 23 de junho de 2015 & $2015-2025^{(*)}$ \\
\hline Paraíba & 10.488 de 23 de junho de 2015 & $2015-2025^{(*)}$ \\
\hline Paraná & 9.479 de 24 de junho de 2015 & $2015-2025$ \\
\hline Pernambuco & 15.533 de 23 de junho de 2015 & $2015-2025^{(*)}$ \\
\hline Piauí & 6.733 de 17 de dezembro de 2015 & $2015-2025^{(*)}$ \\
\hline Rio Grande do Norte & 10.049 de 27 de janeiro de 2016 & $2015-2025$ \\
\hline Rio Grande do Sul & 13.005 de 25 de junho de 2015 & $2015-2025^{(*)}$ \\
\hline Rondônia & 3.565 de 3 de junho de 2015 & 2014-2024 \\
\hline Roraima & 1.008 de 3 de setembro de 2015 & 2014-2024 \\
\hline Santa Catarina & 16.794 de 14 de dezembro de 2015 & $2015-2024$ \\
\hline São Paulo & 16.279 de 8 de julho de 2016 & $2016-2026^{(*)}$ \\
\hline Sergipe & 8.025 de 04 de setembro de 2015 & $2015-2025^{(*)}$ \\
\hline Tocantins & 2.977 de 8 de julho de 2015 & $2015-2025$ \\
\hline
\end{tabular}

FONTE: Elaborado pelo autor.

${ }^{(*)}$ Período não explicitado na lei e nem no documento do PEE correspondente, deduzido a partir da data de publicação do plano e da indicação do seu prazo de vigência (para todos os casos, decenal).

${ }^{(* *)}$ Período não explicitado na lei e nem no documento do PEE correspondente, sem possibilidade de ser deduzido a partir da data de publicação do plano por não haver indicação do seu prazo de vigência.

Ainda com base no Quadro 1, é possível inferir que quase a metade desses PEEs $11(46 \%)$ - explicita em seus documentos (na lei ou no plano propriamente dito) o intervalo de tempo de sua duração, enquanto que uma segunda fração- $11(46 \%)$ - apenas assinala que o plano entra em vigor a partir da data de sua publicação, como de praxe dos textos legislativos, tendo-se deduzido o período em questão considerando a data de publicação do PEE e a indicação do tempo total de vigência explicitado (dez anos). Somente dois planos (8\%), Maranhão e Mato Grosso, não permitiram fixar este intervalo de tempo por não constar em seus documentos qualquer determinação sobre o prazo total de duração do PEE.

Todavia, notam-se algumas variações relativas à notação empregada para o período de duração de alguns desses planos, nomeadamente os do Acre e de Santa Catarina. Ambos indicam o período de vigência 2015-2024 na própria ementa da respectiva lei - "Aprova o Plano Estadual de Educação para o decênio 2015-2024 [...]" (ACRE, 2015; SANTA CATARINA, 2015) -, incluindo na contagem do decênio, portanto, o ano (completo) de publicação do plano propriamente dito. Nestes termos, baseiam-se na notação empregada no PNE 2001-2010 e não na adotada pelo PNE 2014-2024, plano ao qual deveriam expor coesão.

Já os planos do Rio Grande do Norte, Roraima e Rondônia expõem inconsistências 
em relação aos períodos de vigência exibidos nos seus documentos. Embora o primeiro e o segundo PEEs explicitem na ementa de suas leis que se tratam de planos para o período, respectivamente, 2015-2025 e 2014-2024, ao lado do terceiro PEE que indica no documento do plano apensado à sua lei que o intervalo de tempo corresponde a 2014-2024, todos vieram a ser aprovados somente em 2016. Isto implica considerar que o PEE do Rio Grande do Norte possui duração de nove anos, enquanto que os planos de Roraima e Rondônia oito anos de vigência, não se tratando, portanto, de planos efetivamente decenais, e que principiam com defasagens de tempo significativas em relação ao PNE 2014-2024.

Cabe ainda frisar que do conjunto desses 24 PEEs, apenas sete (29\%) fornecem referências a respeito do seu processo de elaboração no estado correspondente, sendo possível distingui-las, de forma pontual e diminuta, nos planos do Acre (2015), Amazonas (2015) e Paraná (2015) ${ }^{6}$, e, de modo sistematizado, com pormenores e em seções específicas destinadas ao registro desses históricos, nos planos de Goiás (2015), Pará (2015), Paraíba (2015) e Rondônia (2015). Ainda em relação àquele total, unicamente nove (38\%) expõem o diagnóstico sobre a realidade educacional do estado na publicação dos seus respectivos planos: além do Acre, Amazonas, Goiás, Pará, Paraná, Paraíba e Rondônia que também registram informações sobre a construção dos seus planos, Maranhão (2014) e Roraima (2015), não havendo, nos demais, qualquer dado a respeito desta etapa investigativa fundamental ao planejamento sistematizado da educação.

\section{O CACS DO FUNDEB}

Em 2006, expirado o prazo de vigência da Lei do Fundo de Manutenção e Desenvolvimento do Ensino Fundamental e de Valorização do Magistério (FUNDEF) - Lei $\mathrm{n}^{\circ}$ 9.424, de 24 de dezembro de 1996 (BRASIL, 1997) ${ }^{7}$-, sua substituição ocorre pelo FUNDEB, criado pela Emenda Constitucional (EC) $\mathrm{n}^{\circ}$ 53, de 19 de dezembro de 2006 (BRASIL, 2006), que, no ano seguinte, veio a ser regulamentada pela Lei $\mathrm{n}^{\circ} 11.494$, de 20 de junho de 2007 (BRASIL, 2007), com prazo de vigência de 14 anos, ou seja, até 2020.

Em linhas gerais, o FUNDEB consiste em um Fundo de natureza contábil, voltado para a gestão financeira de recursos para a Educação Básica, que passou a reunir, a partir do seu terceiro ano de vigência (2009), 20\% de determinados impostos repartidos entre os governos estaduais, municipais e do Distrito Federal, isto em função de critérios legais e com base no quantitativo de matrículas registrado pelo censo escolar neste nível de educação, em ano anterior, levado a efeito pelo Instituto Nacional de Estudos e Pesquisas Educacionais Anísio Teixeira (INEP/MEC) (BRASIL, 2007).

Resultado de um amplo processo reivindicatório por parte de diversas entidades da sociedade civil, direta e indiretamente vinculadas à área da educação, assim como de múltiplos debates na esfera do Poder Executivo e Legislativo Federal, o FUNDEB veio a considerar, para efeito da distribuição dos seus recursos, não apenas o Ensino Fundamental - como no FUNDEF -, mas a Educação Básica como um todo, em suas diversas etapas e modalidades, abarcando a Educação Infantil, o Ensino Fundamental, o Ensino Médio (inclusive integrado à Educação Profissional) a Educação de Jovens e Adultos, a Educação Especial, Indígena e Quilombola (BRASIL, 2007). Tal aumento de cobertura, por um lado, implicou incremento (escalonado em três anos, de 2007 a 2009) do percentual incidente sobre a mesma base de recursos do FUNDEF (de 15\% para 20\%), e, por outro, aumento desta base de quatro para sete fontes (CALLEGARI, 2008).

Do mesmo modo que registrado na Lei do FUNDEF (BRASIL, 1997) ${ }^{9}$, a Lei $\mathrm{n}^{\text {o }}$ 11.494/2007 prevê que o acompanhamento e controle social sobre a "distribuição, a 
transferência e a aplicação dos recursos dos Fundos serão exercidos, junto aos respectivos governos, no âmbito da União, dos Estados, do Distrito Federal e dos Municípios, por conselhos instituídos especificamente para esse fim" (BRASIL, 2007, art. 24), ou seja, pelos CACS do FUNDEB. Porém, diferentemente dos CACS daquele primeiro Fundo, em âmbito federal, o Conselho do FUNDEB deverá ser composto por no mínimo 14 membros; em âmbito estadual, por no mínimo 12; enquanto que no Distrito Federal e na esfera municipal, embora com representações distintas, por no mínimo nove membros cada (BRASIL, 2007, art. 24, § 1 ${ }^{\circ}$, Incisos I, II, III e IV). Em âmbito municipal, além desses quantitativos e de suas respectivas representações, quando a localidade possuir CME e/ou Conselho Tutelar, o CACS deverá ainda incorporar um representante de cada um desses Conselhos locais (BRASIL, 2007, art. 24, $\S 2^{-}$), podendo também vir a integrar-se ao CME por meio da constituição de câmara específica, com competência deliberativa e terminativa, com vista ao "acompanhamento e o controle social sobre a distribuição, a transferência e a aplicação dos recursos do Fundo" (BRASIL, 2007, art. 37).

Em paralelo às contas relativas ao FUNDEB, seu CACS passa também a acompanhar a aplicação de alguns dos recursos federais transferidos aos estados, Distrito Federal e municípios pelo Fundo Nacional de Desenvolvimento da Educação (FNDE), como o Programa Nacional de Apoio ao Transporte do Escolar (PNATE) ${ }^{10}$ e o Programa de Apoio aos Sistemas de Ensino para Atendimento à Educação de Jovens e Adultos ${ }^{11}$ (BRASIL, 2007, art. 24, § 13).

Para Amaral (2012), os CACS do FUNDEB apresentam um maior potencial de vir a ser constituir menos governamental, como foi o do FUNDEF, especialmente em face de alguns avanços na legislação pertinente. Nela, se observa detalhamentos relativos à definição de restrições que impedem determinados indivíduos que tenham ligações com governantes de virem a integrar o Conselho (BRASIL, 2007, art. 24, § 5 ${ }^{-}$), assim com a determinação de que o seu presidente deverá "será eleito por seus pares em reunião do colegiado, sendo impedido de ocupar a função o representante do governo gestor dos recursos do Fundo no âmbito da União, dos Estados, do Distrito Federal e dos Municípios" (BRASIL, 2007, art. 24, $\left.\S 6^{\circ}\right)^{12}$. A lei, igualmente, deixa claro que os CACS "atuarão com autonomia, sem vinculação ou subordinação institucional ao Poder Executivo local" (BRASIL, 2007, art. 24, $\S 7^{\circ}$ ) e que, dentre outros importantes aspectos, a atuação dos membros conselheiros não será remunerada, sendo "considerada atividade de relevante interesse social" (BRASIL, 2007, art. 24, § $7^{\underline{0}}$ ).

Em que pesem as inovações elencadas em torno dos CACS do FUNDEB, algumas exprimindo esforços que visam à superação, pelo menos no plano legal, de problemas crônicos relativos aos CACS do fundo antecessor, ao que tudo indica, muitas continuam sendo as dificuldades e limitações desses Conselhos. Segundo Davies (2008): i) esses CACS seguem espelhando caráter tipicamente estatal e não social, já que possuem mais representantes do Estado do que da sociedade civil propriamente dita (à exceção de sua configuração municipal); ii) na sua composição, apenas os representantes não-estatais não são remunerados, pois os estatais o são na medida em que exercem o cargo de conselheiros durante o horário concernente à jornada normal de trabalho; e, ainda, iii) as limitações postas à capacitação técnica dos conselheiros em face da análise dos documentos contábeis enfraquecem a representação dita social nos CACS. De modo igualmente crítico, Pinto (2008) destaca que: i) o acompanhamento dos recursos do FUNDEB deveria ocorrer não por intermédio de um segundo Conselho, como no caso dos CACS, mas na esfera do próprio CME; ii) uma maior importância legal deveria ser atribuída também ao modo pelo qual o poder de voto divide-se entre os segmentos representados, pois no formato vigente, mesmo sem ocupar a presidência do conselho, o Poder Executivo pode continuar estabelecendo 
controle sobre o colegiado; e, por fim, iii) o fato de a lei continuar a impedir que os CACS possuam estrutura administrativa própria, segue contribuindo para a manutenção da sua dependência em relação a este Poder ${ }^{13}$.

Além dos aspectos acima apontados, problemas similares aos que marcaram a trajetória do FUNDEF ${ }^{14}$ começam a se fazer notar. A título de exemplo, de acordo com reportagem de Vasconcelos (2011), quase a metade dos recursos do FUNDEB no Estado do Rio de Janeiro estavam sendo repassados para Municípios que se encontram com os seus CACS em situação irregular junto ao MEC, ou simplesmente não existiam (VASCONELOS, 2011) ${ }^{15}$.

\section{OS CACS DO PNAE}

O PNAE - também cognominado Programa de Merenda Escolar - se constitui numa das mais antigas ações sociais do governo brasileiro na área de educação, cujas origens remetem aos idos de 1940. Presentemente, se afigurando como parte integrante de um conjunto específico de ações supletivas da União em relação aos estados e municípios, geridas pelo FNDE, seus recursos contemplam os alunos que constam do Censo Escolar relativo ao ano anterior ao atendimento, relativo a todas as etapas da Educação Básica (Educação Infantil, Ensino Fundamental e Ensino Médio) e à modalidade de Educação de Jovens e Adultos (EJA) matriculados em escolas públicas, estaduais, municipais, do Distrito Federal, assim como naquelas mantidas por entidades filantrópicas e pela União ${ }^{16}$.

A descentralização do PNAE principiou, em 1993, primeiramente pela via de sua estadualização e, em seguida, municipalização. Em 1994, a extinta Fundação de Assistência ao Estudante (FAE) - cujas atribuições, a partir de 1997, vieram a ser incorporadas pelo FNDE - já havia repassado aos estados a função de aquisição e distribuição dos gêneros alimentícios da merenda escolar (CARVALHO; VERHINE, 1999; SPINELLI, 1998). Logo depois, em 1999, ocorreu a transferência automática dos recursos financeiros às entidades executoras, à margem da necessidade do estabelecimento de convênios com o FNDE Medida Provisória (MP) $\mathrm{n}^{\circ}$ 1.784, de 14 de dezembro de 1998 (BRASIL, 1998), regulamentada pela Resolução FNDE/CD n 15, de 25 de agosto de 2000 (BRASIL, MEC, FNDE, 2000). A partir daí, tornou-se obrigatória a constituição de órgãos colegiados voltados para o acompanhamento e fiscalização da sociedade em torno da aplicação dos recursos associados ao PNAE, isto pela via da criação dos Conselhos de Alimentação Escolar (CAEs) - aqui também referenciados como CACS do PNAE -, em paralelo às atribuições de controle por parte do FNDE, do Tribunal de Contas da União (TCU), da Secretaria Federal de Controle Interno (SFC) da Controladoria Geral da União (CGU) e do Ministério Público (MP).

Contudo, para Pipitone (1997), a descentralização do PNAE parece vir de modo a potencializar as condições dos municípios bem estruturados e, a um só tempo, aprofundar a deficiência de estrutura técnico-administrativa daqueles considerados pobres e/ou pequenos, apontando tanto a inexistência dos CAEs em determinadas localidades que recebem a transferência desses recursos, quanto às deficiências daqueles onde eventualmente se encontram implantados, nos quais, de acordo com as propostas de descentralização, a comunidade deveria estar participando ativamente dos processos decisórios.

Em 2001, a MP n 2.178-36, de 24 de agosto de 2001 (BRASIL, 2001b), reedita, entre outros aspectos, em seu art. $3^{\circ}$, a obrigatoriedade e as condições de criação dos CAEs enquanto órgão deliberativo, fiscalizador e de assessoramento, a ser constituído, nas esferas estadual, do Distrito Federal e municipal, por sete membros: um representante do poder 
executivo, um do poder legislativo, dois representantes dos professores, dois de pais de alunos e, por fim, um representante de outro segmento da sociedade local. Nos territórios que possuíssem mais de 100 escolas de Ensino Fundamental, a MP facultava a ampliação desta composição para, no máximo, 21 conselheiros, observando-se a proporcionalidade dos segmentos representados na sua configuração básica.

Até a aprovação da Lei $\mathrm{n}^{\circ}$ 11.947, de 16 de junho de 2009 (BRASIL, 2009a), não se identifica lei específica para o PNAE, cuja regulamentação veio se dando pontualmente pela reedição de MPs por parte do Governo Federal e pela via de Resoluções do MEC. Nesta data, portanto, a MP n ${ }^{\circ}$ 455, de 28 de janeiro de 2009 (BRASIL, 2009b) será convertida na lei vigente - Lei $n^{\circ}$ 11.947/2009 (BRASIL, 2009a) -, mantendo as mesmas funções do CAE constantes da MP $\mathrm{n}^{\circ}$ 2.178-36/2001 (BRASIL, 2001b), anteriormente elencadas. Acrescentará, entretanto, a qualidade de órgão colegiado "permanente" ao CAE, agora a ser composto, no mínimo, por um representante indicado pelo Poder Executivo do respectivo ente federado; dois representantes das entidades de trabalhadores da educação e de discentes; dois representantes de pais de alunos e outros dois indicados por entidades civis organizadas, sendo facultada aos estados, ao Distrito Federal e aos municípios a ampliação da composição em questão, desde que obedecida esta proporcionalidade (BRASIL, 2009a, art. 18, Incisos I, II, III e IV).

Ainda no que remete ao art. 18 da Lei $n^{\circ} 11.947 / 2009$, nos demais parágrafos encontra-se previsto: a suplência do segmento representado (BRASIL, 2009a, art. 18, §2 $2^{\circ}$ ), o mandato de quatro anos para os conselheiros, com possibilidade de recondução (BRASIL, 2009a, art. $\left.18, \S 3^{\circ}\right)$, as condições para o exercício da presidência e vice-presidência (BRASIL, 2009a, art. 18, $\S 4^{\circ}$ ), a não remuneração da atividade conselheira - entendida como "serviço público relevante" (BRASIL, 2009a, art. 18, §5º), além da obrigatoriedade de os entes federados informarem ao FNDE a composição adotada para o funcionamento dos seus respectivos CAEs (BRASIL, 2009a, art. 18, $\S 6^{\circ}$ ).

Contudo, apesar de o CAE afirmar-se enquanto espaço de gestão compartilhada entre poder público e sociedade, membros do governo chegaram a admitir que "A sociedade civil ainda participa pouco das instâncias de controle das políticas relacionadas à alimentação escolar" (BALABAN, 2006, p. 39), entendendo que, apesar do pouco tempo da experiência em torno da descentralização dos recursos, "o controle social do PNAE ainda carece de dispositivos formais de atuação da sociedade e [...] que esses dispositivos necessitam maior agilidade" (BALABAN, 2006, p. 39) e ampla divulgação social. A título de exemplo, o estudo desenvolvido por Souza (2006b) junto a 28 municípios do estado do Rio de Janeiro revelou, dentre outros problemas, a ingerência direta do poder público local no funcionamento desses Conselhos, ações pontuais e de curta duração no âmbito da capacitação dos conselheiros, ao lado de disputas entre segmentos sociais que os compõem. Para Pipitone et al. (2006, p. 114), de um lado, o PNAE sugere "necessitar de uma revisão em seus indicadores de supervisão, controle e avaliação" e, de outro, seus Conselhos "precisam revitalizar suas funções alicerçados no comprometimento com a sociedade e com a promoção do PNAE [...]"17.

Como consequiência não apenas dos graves problemas que marcam o funcionamento dos CAEs no País, mas também em função daqueles inerentes aos demais órgãos públicos de fiscalização e à disseminação da cultura da impunidade, os recursos transferidos pela União, por exemplo, aos municípios, há muito vêm sendo alvo de "licitações fraudulentas" ou, em muitos casos, nem chegam "a ter o uso comprovado, desaparecendo dos orçamentos" (REMÍGIO, 2011, p. 13). A reportagem de Remígio (2011) destaca, ainda, que de janeiro de 2008 a junho de 2011, o TCU identificou o mau uso de cerca de R \$ 35 milhões em recursos repassados pela União, além de ter encontrado "merenda de má 
qualidade [...] e lotes entregues com quantidades inferiores às indicadas nos processos de licitação", irregularidades "maquiadas por notas fiscais frias e valores superfaturados" (REMÍGIO, 2011, p. 13). Mais recentemente, em 2016, a participação de políticos num esquema de desvio de dinheiro da merenda escolar está sendo alvo de investigação pelo MP estadual de São Paulo, havendo suspeita de que tenha sido utilizado em campanhas eleitorais. Os indícios levam a crer "que pelo menos 20 prefeituras de São Paulo pagaram mais caro pela merenda servida em creches e escolas públicas"18. Denúncias similares são igualmente trazidas a público por Vasconcelos (2011), Pipitone et al. (2006), Castilho e Souza (2004), dentre outros.

\section{OS CACS DO FUNDEB E DO PNAE NO PNE E NOS PEES}

Assim como no PNE 2014-2024 (BRASIL, 2014), a previsão do acompanhamento e controle social da educação nos 24 PEEs em tela se faz notar tanto de forma genérica, como princípio de regulação social local da educação articulado ao fortalecimento da gestão democrática, quanto de modo específico, situando institucional e sociopoliticamente os CACS como órgãos privilegiados para o monitoramento dos recursos aplicados nesta área das políticas sociais, mas sem perder de vista as competências dos CMEs, dos Conselhos Escolares e demais instâncias colegiadas e de participação que, no presente artigo, fogem ao escopo das análises.

Do ponto de vista do sentido mais amplo atribuído ao acompanhamento e controle social da educação, a Meta 7 do PNE 2014-2024, que versa sobre a problemática da qualidade da Educação Básica, em suas etapas e modalidades, assinala na Estratégia 7.28 a importância de mobilização, em particular, das famílias e, em geral, da sociedade civil, de forma que a educação venha a ser "assumida como responsabilidade de todos" e, a um só tempo, que implique ampliação do "controle social sobre o cumprimento das políticas públicas educacionais" (BRASIL, 2014). Com redação similar a adotada neste PNE, e nas mais variadas metas, tal perspectiva é reafirmada na grande maioria dos PEEs sob análise ${ }^{19}$, ou seja, em 22 (92\%) dos 24 planos, não constando apenas dos PEEs de Goiás (2015) e de Pernambuco (2015).

Comparativamente ao PNE 2001-2010 (BRASIL, 2001a), as referências ao CACS no PNE 2014-2024 (BRASIL, 2014) também ocorrem ao longo do texto do plano, mas com baixa frequência ${ }^{20}$ e menor ênfase em torno do papel a ser desempenhado na esfera do planejamento nacional e subnacional da educação. Neste novo PNE, tais menções são observadas apenas em relação à capacitação dos conselheiros e ao apoio financeiro e logístico a este órgão nas Metas 19 e 20, mais adiante tomadas por referência para efeito da análise do papel desses Conselhos nos PEEs enfocados, que considerará, ainda, a identificação de outras proposições consignadas nas demais metas desses mesmos planos estaduais.

\section{Os CACS nas metas de gestão democrática da educação}

Na Meta 19 do PNE 2014-2024, concernente à efetivação da gestão democrática ${ }^{21}$, a Estratégia 19.2 aponta tanto a importância da ampliação dos programas de apoio e formação dos conselheiros atuantes nos mais variados conselhos de educação, em especial nos CACS do FUNDEB e do PNAE, quanto o apoio financeiro e logístico a este órgão, visando: 
ampliar os programas de apoio e formação aos (às) conselheiros (as) dos conselhos de acompanhamento e controle social do Fundeb, dos conselhos de alimentação escolar, dos conselhos regionais e de outros e aos(às) representantes educacionais em demais conselhos de acompanhamento de políticas públicas, garantindo a esses colegiados recursos financeiros, espaço físico adequado, equipamentos e meios de transporte para visitas à rede escolar, com vistas ao bom desempenho de suas funções (BRASIL, 2014, Estratégia 19.2).

Tal definição de meios e processos ${ }^{22}$ para a consecução da gestão democrática nos sistemas de ensino do País é possível de ser observada na quase totalidade das estratégias formuladas para esta meta nos 24 PEEs em foco, à exceção dos PEEs de Mato Grosso, Pernambuco e do Maranhão. No primeiro, não constam referências diretas aos CACS em nenhuma das suas metas e estratégias, haja vista a publicação deste PEE no DO excluída das decisões relacionadas, entre outras, à gestão democrática e ao financiamento da educação (MATO GROSSO, 2014), conforme sinalizado anteriormente. O segundo plano não estabelece qualquer menção aos CACS na sua respectiva meta de gestão democrática (PERNAMBUCO, 2015, Meta 19), enquanto que o terceiro, embora postulando a criação e/ou consolidação de espaços colegiados consultivos e deliberativos, entre outros, como o CACS do FUNDEB e do PNAE (MARANHÃO, 2014, Estratégias 20.4 e 20.6), se furta, em consonância à Estratégia 19.2 do novo PNE, a prever ações concretas de apoio à formação conselheira, tampouco a se comprometer com as condições materiais que viabilizem o funcionamento institucional desses mesmos conselhos.

Nos demais 21 PEEs constata-se que cerca de dois terços (62\%) reproduzem, praticamente na íntegra, o conteúdo da Estratégia 19.2 do PNE, acima transcrita, como no caso do Acre (2015), Alagoas (2016), Amapá (2015), Bahia (2016), Ceará (2016), Espírito Santo (2015), Goiás (2015), Mato Grosso do Sul (2014), Paraíba (2015), Piauí (2015), Rio Grande do Sul (2015), Rondônia (2015), Roraima (2015), Santa Catarina (2015) e São Paulo (2016). Todavia, desse conjunto, poucos são os planos que avançam no detalhamento de outras estratégias complementares, que poderiam dar mais corpo aos processos e meios que viabilizarão a ampliação dos programas de apoio e formação desses conselheiros no estado, assim como o suporte financeiro e logístico, de modo a conferir maior especificidade à meta de gestão democrática correspondente. São exemplos, o PEE de Alagoas (2016, Estratégia 19.9), que postula "Instituir uma política permanente de formação de conselheiros [...] em regime de colaboração, com recursos disponíveis para estruturação de equipes de técnicos nas redes de ensino [...]", assim como, em especial, o do Amapá (2015, Estratégia 25.7), que destaca o assegurar das condições de "funcionamento autônomo" aos conselhos de acompanhamento das políticas públicas e ao Fórum Estadual de Educação (FEE) - o único PEE a sublinhar a importância da autonomia do CACS para o cumprimento de suas atribuições -, "dotando-os de estrutura física adequada, recursos humanos, materiais, equipamentos, veículos para cumprimento de diligências, dentre outros elementos de manutenção".

Na segunda fração desses 21 planos (38\%), observa-se a reprodução parcial da Meta 19 do PNE 2014-2024 (BRASIL, 2014), singularmente suprimindo a porção do texto que se relaciona ao apoio financeiro e logístico ao funcionamento institucional dos CACS, mantendo apenas a proposta de expansão dos programas de apoio e formação de conselheiros, como no caso do Amazonas (2015), Pará (2015), Paraná (2015), Rio Grande do Norte (2016), Sergipe (2015) e Tocantins (2015). Desse grupo, alguns chegam a nomear outras instâncias colegiadas a serem abarcadas com tais programas, além do CACS do 
FUNDEB e do PNAE, como os Conselhos de Educação (PARÁ, 2015, Estratégia 19.1) os Conselhos de Meio Ambiente e de Saúde (PARANÁ, 2015, Estratégia 19.11), os Conselhos Escolares, Grêmios Estudantis, Conselho de Educação Escolar Indígena e Conselhos Municipais e Estadual de Educação (TOCANTINS, 2015, Estratégia 22.2).

Ainda na esfera das metas vinculadas à gestão democrática do conjunto de PEEs sob análise, nota-se que determinados planos também se ocupam em destacar como estratégia a criação de novos espaços e/ou a consolidação das instâncias vigentes, como o CACS do FUNDB e do PNAE, com vistas à ampliação do controle social sobre o cumprimento das políticas educacionais no estado, como no caso do Pará (2015), de Santa Catarina (2015), de Roraima (2015) e do Maranhão (2014) ${ }^{23}$.

Importante destacar que entre os sete PEEs que incluem na publicação dos seus respectivos planos o diagnóstico sobre a realidade educacional do estado, anteriormente mencionados, o do Amazonas consiste no único que realiza um balanço sobre a situação dos CACS no estado, informando que dos seus 62 municípios " $85 \%$ tem Conselho Municipal de Educação; $90 \%$ deles têm conselho de controle e acompanhamento social pelo FUNDEB e 90\% tem [sic] conselho de alimentação escolar." (AMAZONAS, 2015, Meta 19, Análise Situacional), reconhecendo que "Mesmo com esses avanços, ainda, existem muitos desafios a serem vencidos para elevar esse número de estabelecimentos de ensino para 100\%" (AMAZONAS, 2015, Meta 19, Análise Situacional). Tecnicamente, exames do gênero poderiam contribuir para que os demais PEEs viessem a elaborar estratégias mais efetivas em torno da difusão e consolidação dos seus CACS, na media em que se calçariam no conhecimento de determinados problemas, dificuldades e perspectivas relacionadas ao acompanhamento e controle social no território correspondente.

\section{Os CACS nas metas de financiamento da educação}

Já na Meta 20 do PNE 2014-2024 (BRASIL, 2014), articulada à ampliação do investimento público em educação pública ${ }^{24}$, o CACS, ao lado de outras iniciativas, desponta na Estratégia 20.4, agora vinculadamente, apenas, ao FUNDEB, nos termos de vir a:

fortalecer os mecanismos e os instrumentos que assegurem [...] a transparência e o controle social na utilização dos recursos públicos aplicados em educação, especialmente a realização de audiências públicas, a criação de portais eletrônicos de transparência e a capacitação dos membros de conselhos de acompanhamento e controle social do Fundeb, com a colaboração entre o Ministério da Educação, as Secretarias de Educação dos Estados e dos Municípios e os Tribunais de Contas da União, dos Estados e dos Municípios (BRASIL, 2014, Estratégia 20.4).

A repercussão desta estratégia nas metas referentes ao financiamento da educação nos PEEs sob análise será textualmente reproduzida na metade desses 24 planos (50\%), como no caso dos PEEs do Acre (2015), Amapá (2015), Bahia (2016), Espírito Santo (2015), Goiás (2015), Mato Grosso do Sul (2014), Paraíba (2015) Piauí (2015), Rio Grande do Sul (2015), São Paulo (2016), Sergipe (2015) e Tocantins (2015). Outro agrupamento de PEEs (17\%) irá indicar meios e processos similares aos mencionados na Estratégia 20.4 do novo PNE (BRASIL, 2014), porém, de forma mais sucinta, como o Maranhão (2014), Rio Grande do Norte (2016), Rondônia (2015) e Santa Catarina (2015).

Além disto, nota-se que outras estratégias são previstas por alguns desses mesmos 
PEEs, reforçando e ampliando o papel do acompanhamento e controle social sobre a aplicação dos recursos destinados à educação como, por exemplo: i) a garantia de que o dirigente municipal e estadual de educação tenha suas ações acompanhadas, controladas e fiscalizadas pelos respectivos conselhos do FUNDEB e pelo Tribunal de Contas (TC) (MATO GROSSO DO SUL, 2014, Estratégia 24; RIO GRANDE DO NORTE, 2016, Estratégia 17; SERGIPE, 2015, Estratégia 20.9); ii) o aperfeiçoamento e ampliação dos mecanismos de acompanhamento da arrecadação de impostos, das transferências de recursos e da contribuição social do salário-educação (RIO GRANDE DO SUL, 2015, Estratégia 20.7; SERGIPE, 2015, Estratégia 20.4; TOCANTINS, 2015, Estratégia 24.3); iii) a expansão e aperfeiçoamento de mecanismos que favoreçam a transparência das receitas e despesas relativas ao total dos recursos destinados à educação pública, por meio do acompanhamento, controle social e fiscalização, também por parte dos CMEs (RIO GRANDE DO SUL, 2015, Estratégia 20.11); a definição e o aperfeiçoamento de mecanismos que articulem os órgãos de fiscalização - Conselhos de Educação, TC e MP (PIAUİ, 2015, Estratégia 20.12) e, ainda, iv) o fomento ao desenvolvimento de programas "de avaliação e acompanhamento da atuação de conselhos e colegiados de controle social" (TOCANTINS, 2015, Estratégia 24.7).

Já os PEEs de Alagoas (2016) e de Roraima (2015) compõem um terceiro grupo de PEEs ( $8 \%$ desses 24 planos). Embora o primeiro PEE não indique consonância imediata em relação à Estratégia 20.4 do novo PNE (BRASIL, 2014), explicita na sua meta sobre financiamento importantes estratégias voltadas para o acompanhamento e controle social dos recursos em educação, entre outras, situando: o CACS do FUNDEB como órgão a responsabilizar-se pelo controle social das "verbas próprias e transferidas do Fundo Social do Pré-sal, royalties e participações especiais, referentes ao petróleo e à produção mineral" a serem destinadas à valorização e carreira dos profissionais da educação (ALAGOAS, 2016, Estratégia 20.18); os Conselhos de Educação e o TC como órgãos de acompanhamento, controle e fiscalização das ações dos dirigentes municipais e estaduais de educação (ALAGOAS, 2016, Estratégia 20.19); e, ainda, a "participação dos profissionais das Universidades e de órgãos de controle e fiscalização dos recursos públicos, para acompanhamento e conferência da aplicação dos recursos financeiros destinados a essas IES estaduais" (ALAGOAS, 2016, Estratégia 20.14), perspectiva esta também compartilhada em estratégias de outros planos como Goiás (2015, Estratégia 15.2) e Roraima (2015, Estratégia $5.1 .22)^{25}$. Por seu turno, o PEE de Roraima (2015), apesar de também não indicar vinculações diretas com o conteúdo da Estratégia 20.4 em questão, não deixa de formular meios relacionados aos órgãos de acompanhamento e controle social dos recursos em educação, quer em função do fato de as estratégias de gestão democrática e de financiamento estarem integradas em uma única meta, tendo implicado, conforme visto anteriormente, considerações relacionadas à Estratégia 19.2 do novo PNE (BRASIL, 2014), quer em decorrência da sinalização da importância do fortalecimento dos mecanismos e dos instrumentos que venham a assegurar a transparência e o controle social da utilização dos recursos públicos em questão (RORAIMA, 2015, Estratégias 12.1.8 e 12.1.34).

Por fim, um quarto grupo de planos (25\%), composto pelos PEEs do Amazonas (2015), Ceará (2016), Mato Grosso (2014), Pará (2015), Paraná (2015) e Pernambuco (2015) não fará nenhuma alusão direta aos CACS nas suas respectivas metas sobre financiamento. Neste sentido, estes planos não irão reforçar a importância e o papel desses órgãos em específico no acompanhamento e controle dos recursos a serem aplicados em educação, em particular do FUNDEB e do PNAE, embora os PEEs do Ceará, Pará e Paraná cheguem a estabelecer algumas estratégias correlatas: o primeiro ao determinar a definição e aperfeiçoamento dos "mecanismos de controle social e de planejamento, execução e 
acompanhamento de receitas e despesas [...]" (CEARÁ, 2016, Estratégia 20.3); o segundo reafirmando a importância em "consolidar as bases da política de financiamento, acompanhamento e controle social da educação pública, em todos os níveis, etapas e modalidades [...]" (PARÁ, 2015, Estratégia 20.4), enquanto que o terceiro plano sinalizando o fortalecimento "em parceria com a União e os municípios, [dos] mecanismos e instrumentos que assegurem a transparência e o controle social, quanto à aplicação de recursos na manutenção e desenvolvimento da educação" (PARANÁ, 2015, Estratégia 20.4).

\section{Os CACS em outras metas}

Segundo demarcação anterior, referências aos CACS no PNE 2014-2024 (BRASIL, 2014) ocorrem, em exclusivo, nas Metas 19 e 20, em duas de suas estratégias, respectivamente, 19.2 e 20.4. Contudo, no âmbito de alguns poucos PEEs sob análise, é possível também identificar-se menção a estes conselhos em outras metas de maior especificidade regional, conforme indicam os planos do Acre, Roraima, Tocantins e Pernambuco.

Nos PEEs do Acre e de Roraima, em metas relacionadas à Educação Indígena, constata-se a preocupação em ampliar a participação das instituições representativas dessa população nos CACS do estado (RORAIMA, 2015, Estratégia 9.1.1) e, além de assegurar a participação em questão, garantir a sua formação (ACRE, 2015, Estratégia 12.27). Já o plano de Tocantins sinaliza a ampliação do papel desses conselhos, de um modo geral, como colaborador na implantação e execução da "política de avaliação e monitoramento da gestão dos recursos financeiros destinados à educação básica das escolas públicas estaduais, das diretorias regionais de educação e da Seduc/TO", relativo à Meta sobre Qualidade da Educação Básica (TOCANTINS, 2015, Estratégia 23.7), e, de forma específica, no âmbito do CACS do PNAE, em termos do desenvolvimento, como parceiro, de programa de segurança alimentar e nutricional articulado à Educação Básica, constante da meta sobre Educação Ambiental (TOCANTINS, 2015, Estratégia 11.7). Já o PEE de Pernambuco, que, conforme visto, consiste no único plano examinado que até agora não veio a indicar qualquer referência a esses conselhos nas metas de gestão democrática e de financiamento da educação, curiosamente traça uma única e breve referência na meta relativa à universalização do Ensino Fundamental, indicando o acompanhamento e a fiscalização, em especial pelos CACS do FUNDEB, da "oferta de transporte escolar, frequência e qualidade" (PERNAMBUCO, 2015, Estratégia 2.10).

\section{CONSIDERAÇÕES FINAIS}

Embora, na prática, por força de lei nacional, os entes federados sejam obrigados a criarem o CACS do FUNDEB - Lei ${ }^{\circ}$ 11.494/2007 (BRASIL, 2007) - e, ainda, caso sejam beneficiários do PNAE, igualmente, comprovar a existência dos CAEs - Lei no 11.947/2009 (BRASIL, 2009a) -, a explicitação normativo-jurídica dos seus papeis, assim como a definição da extensão e amplitude das atribuições desses conselhos, parece revestir-se de importância fundamental para o planejamento da educação, quer de modo a reafirmar o valor da participação sociopolítica nesses órgãos colegiados, contribuindo para o processo de desenvolvimento da gestão democrática, quer com vistas à garantia do acompanhamento e controle social da aplicação dos recursos públicos destinados à educação, concorrendo, 
assim, para a promoção de maior transparência na gestão pública.

Todavia, conforme já discutido, são muitos os problemas que ainda marcam o funcionamento institucional e sociopolítico dos CACS no País, evidenciados, seja em função de determinadas características estruturais desses conselhos , a priori, constantes do ordenamento jurídico que baliza a sua criação, seja em decorrência da sua ressignificação local, quando incorpora as virtudes e os deméritos da cultura política que o contextualiza, seja a partir de constatações relativas ao adensamento de fraudes sobre os recursos correlatos ao FUNDEB e ao PNAE. Em larga medida, os PEEs até aqui analisados sugerem contribuir muito pouco para a superação deste quadro.

Retrospectivamente, de modo sintonizado à meta relativa à gestão democrática do PNE 2014-2024 (BRASIL, 2014, Meta 19), nota-se, entre os planos examinados, a recorrência de demarcações em torno da importância dos programas de apoio e formação dos conselheiros desses CACS, embora se furtando à explicitação das políticas e práticas que darão corpo a essa estratégia, espelhando mais a reprodução do texto homólogo daquele plano nacional do que propriamente a caracterização autoral de alguma ação pública específica do estado. Neste sentido, são poucos os planos que avançam, assim como aqueles que explicitam a disposição em criar novos espaços e/ou consolidar as instâncias colegiadas vigentes, também omitindo o comprometimento para com o suporte financeiro e logístico que viabiliza o funcionamento local dessas instâncias. Além disto, conforme visto, coexistem PEEs que sequer mencionam os CACS nas estratégias relacionadas à gestão democrática, sendo que apenas um único plano chega efetuar diagnóstico sobre a situação dos CACS no estado, a nosso ver, etapa pré-requisita fundamental para a definição de qualquer estratégia relacionada a esses conselhos.

Será apenas nas estratégias que dão sustento à meta de financiamento da educação que se observará alguma definição do papel a ser cumprido pelos CACS nesses PEEs, em particular do FUNDEB, mas, de forma equivalente ao que ocorreu no âmbito da meta de gestão democrática, caracteristicamente por meio da reprodução textual (integral ou parcial) do conteúdo relativo ao PNE 2014-2024 (BRASIL, 2014, Meta 20), sendo escassos os planos que irão reforçar e ampliar nas estratégias em questão o papel do acompanhamento e controle social sobre a aplicação dos recursos públicos em educação, a par daqueles que não realizam nenhuma alusão a esses CACS.

De um modo ou de outro, as análises relativas ao conjunto total dos PEEs alvos deste estudo evidenciam reduzido valor institucional e sociopolítico dos CACS do FUNDEB e, sobretudo, do PNAE no âmbito dos sistemas de ensino e, em particular, na esfera do planejamento estadual da educação, quer em função do formalismo e/ou da superficialidade refletidos no conjunto das estratégias identificadas, quer, de forma ainda mais crítica, em decorrência das sucessivas omissões de referências a estes órgãos colegiados em muitos desses planos, lacunas que se estendem da indefinição do seu papel, passando pelos hiatos de caracterização dos espaços de sua atuação, culminando no absenteísmo relativo ao apoio financeiro e logístico a estes conselhos.

Finalmente, postula-se que, no âmbito do planejamento da educação pública, a importância do papel a ser desempenhado pelos CACS, ao lado dos órgãos públicos de fiscalização e controle (TCs, Controladorias, MPs, entre outros), é inegável, isto não apenas com vistas à construção e consolidação do processo de gestão democrática da educação no País, mas, essencialmente, em face da viabilização do próprio plano de educação, já que, para a consecução das políticas que sustentam as suas decisões, este depende, sobremaneira, do efetivo direcionamento e da correta aplicação dos recursos públicos correspondentes. Em outras palavras, de que adianta um plano de educação técnica e politicamente bem estruturado, inclusive juridicamente garantido por vinculação orçamentária constitucional, 
se o controle sobre a aplicação dos recursos financeiros se mostra duvidoso tanto no domínio do poder público, quanto no horizonte do acompanhamento social?

\section{REFERÊNCIAS}

ACRE (Estado). Lei no 2.965, de 2 de julho de 2015. Aprova o Plano Estadual de Educação para o decênio 2015-2024 e dá outras providências. Diário Oficial [do] Estado de Acre, Rio Branco, 03 jul. 2015.

ALAGOAS (Estado). Lei no 7.795, de 22 de janeiro de 2016. Aprova o Plano estadual de Educação PEE, e dá outras providências. Diário Oficial [do] Estado de Alagoas, Maceió, 25 jan. 2016.

AMAPÁ (Estado). Lei no 1.907, de 24 de junho de 2015. Dispõe sobre o Plano Estadual de Educação - PEE, para o decênio 2015 -2025, e dá outras providências. Diário Oficial [do] Estado do Amapá, Macapá, 24 de junho de 2015.

AMARAL, Nelson Cardoso. Para compreende o financiamento da educação básica no Brasil. Brasília: Liber Livro, 2012.

AMAZONAS (Estado). Lei no 4.183, de 26 de junho de 2015. Aprova o Plano Estadual de Educação do Estado do Amazonas e dá outras providências. Diário Oficial [do] Estado do Amazonas, Manaus, 26 jun. 2015.

ARRETCHE, Marta. Políticas sociais no Brasil: descentralização em um estado federativo. Revista Brasileira de Ciências Sociais, São Paulo, v. 14, n. 40, p. 111-141, jun. 1999.

Relações federativas nas políticas sociais. Educação \& Sociedade, Campinas, v. 23, n. 80 , p. $25-48$, set. 2002.

AZEVEDO, Janete Maria Lins de. Implicações da nova lógica de ação do Estado para a educação municipal. Educação \& Sociedade, Campinas, v. 23, n. 80, p. 49-71, set. 2002.

BAHIA (Estado). Lei no 13.559, de 11 de maio de 2016. Aprova o Plano Estadual de Educação da Bahia e dá outras providências. Diário Oficial [do] Estado da Bahia, Salvador, 12 maio 2016.

BALABAN, Daniel Silva. A importância de conselhos de alimentação escolar: o controle de políticas públicas sob a ótica da cidadania. In: SOUZA, Donaldo Bello de. (Org.). Acompanhamento e controle social da educação: fundos e programas federais e seus conselhos locais. São Paulo: Xamã, 2006, p. 29-40.

BARDIN, Laurence. Análise de conteúdo. 4. ed. Lisboa: Edições 70, 2004.

BORDIGNON, Genuíno. Planos de governo e políticas de estado: muitos planos, pouco planejamento. In: SOUZA, Donaldo Bello de; MARTINS, Ângela Maria (Org.). Planos de educação no Brasil: planejamento, políticas, práticas. São Paulo: Edições Loyola, 2014, p. 29-53.

BRAGA. Marcus Vinicius de Azevedo. O controle social da educação básica pública: a atuação dos conselheiros do Fundeb. Brasília, DF, 2011, 176f. Dissertação (Mestrado em Educação) - Faculdade de Educação, Universidade de Brasília, 2011.

BRASIL. Constituição [de 1988] da República Federativa do Brasil. Diário Oficial da União [da] República Federativa do Brasil, Brasília, DF, 5 out. 1988. 
BRASIL. Decreto-lei $n^{\circ} 4.657$, de 4 de setembro de 1942. Lei de Introdução ao Código Civil Brasileiro. Diário Oficial da União [da] República Federativa do Brasil, Brasília, DF, 9 set. 1942.

Emenda Constitucional no 53, de 19 de dezembro de 2006. Dá nova redação aos arts. $7^{\circ}, 23,30,206,208,211$ e 212 da Constituição Federal e ao art. 60 do Ato das Disposições Constitucionais Transitórias. Diário Oficial [da] República Federativa do Brasil, Brasília, DF, 20 dez. 2006.

Lei $\mathrm{n}^{\circ}$ 10.172, de 09 de janeiro de 2001. Aprova o Plano Nacional de Educação (PNE). Diário Oficial da União [da] República Federativa do Brasil, Brasília, DF, 10 jan. 2001a.

Lei $\mathrm{n}^{\mathrm{o}}$ 10.880, de 9 de junho de 2004. Institui o Programa Nacional de Apoio ao Transporte do Escolar - Pnate e o Programa de Apoio aos Sistemas de Ensino para Atendimento à Educação de Jovens e Adultos, dispõe sobre o repasse de recursos financeiros do Programa Brasil Alfabetizado. Diário Oficial [da] República Federativa do Brasil, Brasília, 11 jun. 2004.

Lei ${ }^{\circ}$ 11.494, de 20 de junho de 2007. Regulamenta o Fundo de Manutenção e Desenvolvimento da Educação Básica e de Valorização dos Profissionais da Educação FUNDEB, de que trata o art. 60 do Ato das Disposições Constitucionais Transitórias; altera a Lei no 10.195, de 14 de fevereiro de 2001; revoga dispositivos das Leis $n^{\circ} 9.424$, de 24 de dezembro de 1996, 10.880, de 9 de junho de 2004, e 10.845, de 5 de março de 2004; e dá outras providências. Diário Oficial [da] República Federativa do Brasil, Brasília, DF, 21 jun. 2007.

Lei $\mathrm{n}^{\mathrm{o}} 11.947$, de 16 de junho de 2009a. Dispõe sobre o atendimento da alimentação escolar e do Programa Dinheiro Direto na Escola aos alunos da educação básica; altera as Leis $\mathrm{n}^{\mathrm{os}} 10.880$, de 9 de junho de 2004, 11.273, de 6 de fevereiro de 2006, 11.507, de 20 de julho de 2007; revoga dispositivos da Medida Provisória $n^{0} 2.178-36$, de 24 de agosto de 2001, e a Lei ${ }^{\circ}$ 8.913, de 12 de julho de 1994; e dá outras providências. Diário Oficial [da] República Federativa do Brasil, Brasília, DF, 17 jun. 2009a.

Lei $n^{\circ} 12.376$, de 30 de dezembro de 2010. Altera a ementa do Decreto-Lei $n^{\circ} 4.657$, de 4 de setembro de 1942. Diário Oficial [da] República Federativa do Brasil, Brasília, DF, 31 dez. 2010.

Lei n ${ }^{\circ} 13.005$, de 25 de junho de 2014. Aprova o Plano Nacional de Educação - PNE e dá outras providências. Diário Oficial [da] República Federativa do Brasil, Brasília, DF, 26 jun. 2014.

Lei no 9.394, de 20 de dezembro de 1996. Estabelece as Diretrizes e Bases da Educação Nacional. Diário Oficial [da] República Federativa do Brasil, Brasília, DF, 23 dez. 1996.

Lei $\mathrm{n}^{\circ}$ 9.424, de 24 de dezembro de 1996. Dispõe sobre o Fundo de Manutenção e Desenvolvimento do Ensino Fundamental e de Valorização do Magistério, na forma prevista no art. $60, \S 7^{\circ}$, do Ato das Disposições Constitucionais Transitórias e dá outras providências. Diário Oficial [da] República Federativa do Brasil, Brasília, DF, 01 jan. 1997.

Medida Provisória no 1.784, de 14 de dezembro de 1998. Dispõe sobre o repasse de recursos financeiros do Programa Nacional de Alimentação Escolar, institui o Programa 
Dinheiro Direto na Escola, e dá outras providências. Diário Oficial [da] República Federativa do Brasil, Brasília, DF, 15 dez. 1998.

. Medida Provisória no 2.178-36, de 24 de agosto de 2001. Dispõe sobre o repasse de recursos financeiros do Programa Nacional de Alimentação Escolar, institui o Programa Dinheiro Direto na Escola, altera a Lei n. ${ }^{\circ}$ 9.533, de 10 de dezembro de 1997, que dispõe sobre programa de garantia de renda mínima, institui programas de apoio da União às ações dos Estados e Municípios voltadas para o atendimento educacional e dá outras providências. Diário Oficial [da] República Federativa do Brasil, Brasília, DF, 25 ago. 2001b.

Medida Provisória n ${ }^{\circ} 455$, de 28 de janeiro de 2009. Dispõe sobre o atendimento da alimentação escolar e do Programa Dinheiro Direto na Escola aos alunos da educação básica, altera a Lei no 10.880 , de 9 de junho de 2004, e dá outras providências. Diário Oficial [da] República Federativa do Brasil, Brasília, DF, 29 jan. 2009b.

Ministério da Educação. Fundo Nacional de Desenvolvimento da Educação. Conselho Deliberativo. Resolução $\mathrm{n}^{\circ}$ 015, de 25 de agosto de 2000. Dispõe sobre os critérios e as formas de transferência e de prestação de contas dos recursos do Programa Dinheiro Direto na Escola - PDDE, destinados ao atendimento das escolas de educação especial, e dá outras providências. Diário Oficial [da] República Federativa do Brasil, Brasília, DF, 30 ago. 2000.

CALDERÓN, Adolfo Ignácio; MARIM, Vlademir. Participação popular: a escola como alvo do terceiro setor. In: SOUZA, Donaldo Bello de; FARIA, Lia Ciomar Macedo de (Orgs.). Desafios da educação municipal. Rio de Janeiro: DP\&A, 2003, p. 211-231.

CALLEGARI, Cesar. Fundeb: financiamento da educação púbica no estado de São Paulo. 3. ed. São Paulo: Ground; Apeoesp, 2008.

CALLEGARI, Cesar; CALLEGARI, Newton. Ensino fundamental: a municipalização induzida. São Paulo: Senac, 1997.

CAMPOS, Bruno Cesar; CRUZ, Breno de Paula Andrade. Impactos do Fundeb sobre a qualidade do ensino básico público: uma análise para os municípios do estado do Rio de Janeiro. Revista de Administração Pública, Rio de Janeiro, v. 43, n. 2, p. 371-393, abr. 2009.

CARVALHO, Inaiá M. M.; VERHINE, Robert E. A descentralização da educação. Sociedade \& Estado, Brasília, v. 14, n. 2, p. 299-322, jul./dez. 1999.

CASSASUS, Juan. Tarefas da educação. Campinas: Autores Associados, 1995.

CASTILHO, Alceu Luís; SOUZA, Marcos de Moura e. Inimigos públicos: vampirismo da corrupção desvia merenda escolar, verbas do Fundef, cria cursos fantasmas de capacitação e se alastra por vários Estados do Brasil. Revista Educação, São Paulo, v. 8, n. 87, p. 42-50, jul. 2004.

CEARÁ (Estado). Lei $\mathrm{n}^{\circ}$ 16.025, 30 de maio de 2016. Dispõe sobre o plano estadual de educação (2016/2024). Diário Oficial [do] Estado do Ceará, Fortaleza, v. 8, n. 101, 30 maio 2016.

CONCEIÇÃO, Sergio Henrique; FIALHO, Nadia Hage. Financiamento, oferta, gestão educacional e controle social no âmbito de um Conselho de Acompanhamento e Controle Social do Fundeb. Revista de Educação Pública, Cuiabá, v. 23 n. 54, p. 783-806, set./dez. 2014. 
COSTA, Jean Mário Araújo; CUNHA, Maria Couto; ARAÚJO, Rosimeire Baraúna M. de. Federalismo cooperativo brasileiro: implicações na gestão da educação municipal. Jornal de Políticas Educacionais, Curitiba, n. 8, p. 14-23, jul./dez., 2010.

CUNHA, Eleonora Schettini M.; THEODORO, Hidelano Delanusse (Orgs.). Desenho institucional, democracia e participação: conexões teóricas e possibilidades analíticas. Belo Horizonte: D’Plácido, 2014

DAVIES, Nicholas. Conselhos do Fundef: a participação impotente. Ensaio - Avaliação e Políticas Públicas em Educação, Rio de Janeiro, v. 11, n. 41, p. 505-517, out./dez. 2003.

Fundeb: a rendenção da educação básica? Campinas: Autores Associados, 2008 (Coleção Polêmicas do Nosso Tempo).

O financiamento da educação estatal no Brasil: velhos e novos desafios. Revista Brasileira de Política e Administração da Educação, Porto Alegre, RS, v.16, n. 2, p. 159176, jul./dez, 2000.

O Fundef e as verbas da educação. São Paulo: Xamã, 2001.

O Fundef e o orçamento da educação: desvendando a caixa preta. Campinas: Autores Associados, 1999.

O Fundef e os equívocos na legislação e documentação oficial. Cadernos de Pesquisa, São Paulo, SP, n. 113, p. 113-128, jul. 2001.

DUARTE, Marisa Ribeiro Teixeira; FARIA, Geniana Guimarães. Recursos públicos para escolas públicas: as políticas de financiamento da educação básica no Brasil e a regulação do sistema educacional federativo. Belo Horizonte: RHJ; Ed.FaE/UFMG, 2010.

ESPÍRITO SANTO (Estado). Lei ${ }^{\circ} 10.382$, de 24 de junho de 2015. Aprova o Plano estadual de Educação do espírito Santo - PEE/ES, período 2015/2025. Diário Oficial [do] Estado do Espírito Santo, Vitória, 25 jun. 2015.

FERNANDES, Maria Dilnéia Espíndola; FERNANDES, Solange Jarcem. O Fundeb no contexto das finanças públicas municipais de Campo Grande. Educação \& Realidade, Porto Alegre, v. 39, n. 3, p. 907-924, set. 2014.

FREY, Klaus. Políticas públicas: um debate conceitual e reflexões referentes à prática da análise de políticas públicas no Brasil. Planejamento e Políticas Públicas, Brasília, DF, n. 21, p. 211-259, jun. 2000.

GABRIEL, Cristine Garcia; MACHADO, Manuella de Souza; SCHMITZ, Bethsáida de Abreu Soares; CORSO, Arlete Catarina Tittoni; CALDEIRAS, Gilberto Veras; VASCONCELOS, Francisco de Assis Guedes de. Conselhos Municipais de Alimentação Escolar em Santa Catarina: caracterização e perfil de atuação. Ciência \& Saúde Coletiva, Rio de Janeiro, v. 18, n. 4, p. 971-978, 2013.

GOHN, Maria da Glória. Conselhos gestores e participação sociopolítica. São Paulo: Cortez, 2001. (Coleção Questões da Nossa Época; 84).

O novo associativismo e o Terceiro Setor. Serviço Social \& Sociedade, São Paulo, v. 19, n. 58, p. 9-23, nov. 1998.

GOIÁS (Estado). Lei no 18.969, de 22 de julho de 2015. Aprova o Plano Estadual de Educação para o decênio 2015/2025 e dá outras providências. Diário Oficial [do] Estado de Goiás, Goiânia, 27 jul. 2015. 
GOMES, Candido Alberto; PASCOALINO, Hélio. O elo (às vezes perdido) da gestão: estudos de caso sobre resultados iniciais do Fundef. Revista Brasileira de Política e Administração da Educação, Porto Alegre, v.16, n. 2, p. 197-211, jul./dez, 2000.

GONÇALVES, Renaldo Antônio. O financiamento da educação: um sistema em desequilíbrio. Cadernos de Pesquisa, São Paulo, n. 103, p. 14-52, mar. 1998.

GOUVEIA, Andréa Barbosa; SILVA, Isabelle Fiorelli. O gasto aluno-ano no Paraná (Brasil) e a situação de financiamento da educação nas regiões metropolitanas do Estado. Perspectiva, Florianópolis, v. 30, n. 1, p. 305-331, abr. 2012.

GURGEL, Claudio; JUSTEN, Agatha. Controle social e políticas públicas: a experiência dos Conselhos Gestores. Revista de Administração Pública, Rio de Janeiro, v. 47, n. 2, p. 357-378, mar./abr. 2013.

KETELE, Jean-Marie de; ROEGIERS; Xavier. Metodologia da recolha de dados: fundamentos dos métodos de observações, de questionários, de entrevistas e de estudo de documentos. Lisboa: Instituto Piaget, 1993.

KRAWCZYK, Nora Rut; VIEIRA, Vera Lucia. A reforma educacional na América Latina nos anos 1990: uma perspectiva histórico-sociológica. São Paulo: Xamã, 2008.

KUGELMAS, Eduardo; SOLA, Lourdes. Recentralização/descentralização: dinâmica do regime federativo no Brasil dos anos 90, fev. 2000. Tempo Social, São Paulo, v. 11, n. 2, p. 63-81, fev. 1999.

LAUGLO, Jon. Formas de descentalización y sus implicaciones para la educación. In: PEREYRA, Miguel A.; MINGUEZ, Jesús García; BEAS, Miguel; GÓMEZ, Antonio J. (Comp.) Globalización y descentralización de los sistemas educativos: fundamentos para un nuevo programa de la educación comparada. Barcelona: Pomares-Corredor, 1996, p. 169-207.

LAVALLE, Adrian Gurza; HOUTZAGER, Peter P.; CASTELLO, Graziela. Representação política e organizações civis: novas instâncias de mediação e os desafios da legitimidade. Revista Brasileira Ciência e Sociedade, São Paulo, v. 21, n. 60, p. 43-66, fev. 2006.

LAVILLE, Christian; DIONNE, Jean. A construção do saber: manual de metodologia da pesquisa em ciências humanas. Porto Alegre: Artmed; Belo Horizonte: Ed.UFMG, 1999.

LUCHMANN, Lígia Helena Hahn. A representação no interior das experiências de participação. Lua Nova: Revista de Cultura e Política, São Paulo, n. 70, p. 139-170, 2007.

MARANHÃO(Estado). Lei no 10.099, de 11 de junho de 2014. Aprova o Plano Estadual de Educação do Estado do Maranhão e dá outras providências. Diário Oficial [do] Estado do Maranhão, São Luiz, 11 jun. 2014.

MARTINS, Ângela Maria (Org.). Estado da Arte: gestão, autonomia escolar e órgãos colegiados (2000/2008). Brasília: Liber; Niterói: Anpae, 2011.

MARTINS, Paulo de Sena. Fundeb, federalismo e regime de colaboração. Campinas: Autores Associados; Brasília, DF: Ed.UnB, 2011.

MATO GROSSO (Estado). Lei $\mathrm{n}^{\circ} 10.111$, de 06 de junho de 2014. Dispõe sobre a revisão e alteração do Plano Estadual de Educação, instituído pela Lei $\mathrm{n}^{\circ}$ 8.806, de 10 de janeiro de 2008. Diário Oficial [do] Estado do Mato Grosso, Cuiabá, 06 jun. 2014. 
MATO GROSSO DO SUL (Estado). Lei $\mathrm{n}^{\circ}$ 4.621, de 22 de dezembro de 2014. Aprova o Plano Estadual de Educação de Mato Grosso do Sul, e dá outras providências. Diário Oficial [do] Estado do Mato Grosso do Sul, Campo Grande, 26 dez. 2014.

MATOS, Antonio Newton Soares e. Fundef: fiscalização e controle social. In: CONFERÊNCIA NACIONAL DE EDUCAÇÃO, CULTURA E DESPORTO, 1, 2001, Brasília, DF. Anais... Brasília, DF: Câmara dos Deputados, Coordenações de Publicações, 2001, p. 423-427.

MENDES, Denise Cristina Vitale Ramos. Representação política e participação: reflexões sobre o déficit democrático. Revista Katálysis, Florianópolis, v. 10, n. 2, p. 143-153, jul./dez. 2007.

MONTAÑO, Carlos. Terceiro setor e questão social: crítica ao padrão de intervenção social. 2. ed. São Paulo: Cortez, 2003.

MULLER, Pierre; SUREL, Yves. L'analyse des politiques publiques. Paris: Editions Montchestien, 1998.

OLIVEIRA, Cleiton; GANZELI, Pedro; GIUBILEI, Sonia; BORGES, Zacarias Pereira. (Orgs.). Conselhos municipais de educação: um estudo na região metropolitana de Campinas. Campinas: Alínea, 2006.

OLIVEIRA, Rosimar de Fátima. O FUNDEF em três dimensões: formulação regulamentação e implementação. Rio de Janeiro: Publit, 2008.

OLIVEIRA, Virgílio Cézar da Silva e, PEREIRA, José Roberto; OLIVEIRA, Vânia A. R. de Os conselhos gestores municipais como instrumentos da democracia deliberativa no Brasil. Cadernos EBAPE.BR, Rio de Janeiro, v. 8, n. 3, p. 422-437, set 2010.

PARÁ (Estado). Lei no 8.186, de 23 de junho de 2015. Aprova o Plano Estadual de Educação - PEE e dá outras providências. Diário Oficial [do] Estado do Pará, Belém, 24 jun. 2015.

PARAÍBA (Estado). Lei no 10.488, de 23 de junho de 2015. Aprova o Plano Estadual de Educação - PEE e dá outras providências. Diário Oficial [do] Estado da Paraíba, João Pessoa, 24 jun. 2015.

PARANÁ (Estado). Lei no 18.492, de 24 de Junho de 2015. Aprovação do Plano Estadual de Educação e adoção de outras providências. Diário Oficial [do] Estado do Paraná, Curitiba, 25 jun. 2015.

PÉRES, Jesús Ignacio; ROITH, Christian; SÂNCHEZ, Antonio. Descentralización y evaluación de los sistemas educativos europeos: um informe del simposio de Granada. In. LÓPEZ-VELARDE, Jaime Calderón (Coord.). Teoría y desarrollo de la investigación en educación comparada. México: Plaza y Valdés, 2000, p. 169-191.

PERNAMBUCO (Estado). Lei $n^{\circ} 15.533$, de 23 de junho de 2015. Aprova o Plano Estadual de Educação PEE. Diário Oficial [do] Estado de Pernambuco, Recife, 24 jun. 2015.

PERONI, Vera. Política educacional e papel do estado no Brasil dos anos 1990. São Paulo: Xamã, 2003.

PIAUÍ (Estado). Lei n ${ }^{\circ}$ 6.733, de 17 de dezembro de 2015. Diário Oficial [do] Estado do Piauí, Teresina, 21 dez. 2015. 
PINTO, José Marcelino de Rezende. O potencial de controle social dos conselhos do Fundef e o que se pode esperar dos conselhos do Fundeb. In: SOUZA, Donaldo Bello de. (Org.). Conselhos municipais e controle social da educação: descentralização, participação e cidadania. São Paulo: Xamã, 2008, p. 153-168.

Federalismo, descentralização e planejamento da educação: desafios aos municípios. Cadernos de Pesquisa, São Paulo, v. 44, n. 153, p.624-644, 2014.

PINTO, José Marcelino de Rezende; ALVES, Thiago. O Impacto financeiro da ampliação da obrigatoriedade escolar no contexto do FUNDEB. Educação \& Realidade, Porto Alegre, v. 36, n. 2, p. 605-624, ago. 2011.

PIPITONE, Maria Angelica. Programa de alimentação escolar: um estudo sobre descentralização, escola e educadores. Campinas, 1997, 281 f. Tese (Doutorado em Educação) - Universidade Estadual de Campinas, 1997.

PIPITONE, Maria Angelica; OMETTO, Ana Maria H.; SILVA, Marina Vieira da; STURION, Ilma Lucazechi. Atribuições e funcionamento dos conselhos municipais de alimentação escolar. In: SOUZA, Donaldo Bello de. (Org.). Acompanhamento e controle social da educação: fundos e programas federais e seus conselhos locais. São Paulo: Xamã, 2006, p. 99-116.

RANGEL, Luiz Silveira. Aspectos institucionais do Programa Nacional de Apoio ao Transporte Escolar (Pnate): normas e controle social. In: SOUZA, Donaldo Bello de. (Org.). Acompanhamento e controle social da educação: fundos e programas federais e seus conselhos locais. São Paulo: Xamã, 2006, p. 53-72.

REMÍGIO, Marcelo. Merenda escolar é desviada de Norte a Sul: pelo menos R\$ 35 milhões foram para o ralo nos últimos três anos, segundo Tribunal de Contas da União. O Globo, Rio de Janeiro, 24 de julho de 2011, O País, p. 13.

RIBEIRO, Andreia Couto; JESUS, Wellington Ferreira de. A trajetória histórica da política pública de transporte escolar: um olhar sob a assistência dos programas federais para a educação básica. Revista HISTEDBR On-line, Campinas, n. 66, p. 135-159, dez. 2015.

RIO GRANDE DO NORTE (Estado). Lei $\mathrm{n}^{\circ}$ 10.049, de 27 de janeiro de 2016. Aprova o Plano Estadual de Educação do Rio Grande do Norte (2015-2025) e dá outras providências. Diário Oficial da União [do] Estado do Rio Grande do Norte, Natal, 27 jan. 2016.

RIO GRANDE DO SUL (Estado). Lei no 14.705, de 25 de junho de 2015. Institui o Plano Estadual de Educação - PEE -, em cumprimento ao Plano Nacional de Educação - PNE -, aprovado pela Lei Federal n. ${ }^{\circ}$ 13.005, de 25 de junho de 2014. Diário Oficial [do] Estado do Rio Grande do Sul, Porto Alegre, n. 120, 26 jun. 2015.

RONDÔNIA (Estado). Lei no 3.565, de 3 de junho de 2015. Institui o Plano Estadual de Educação de Rondônia. Diário Oficial [do] Estado de Rondônia, Porto Velho, 3 de junho de 2015.

RORAIMA (Estado). Lei ${ }^{\circ} 1.008$, de 3 de setembro de 2015. Aprova o Plano Estadual de Educação 2014-2024 (PEE) e dá outras providências. Diário Oficial [do] Estado de Roraima, Boa Vista, 3 de setembro de 2015.

SALES, Luis Carlos e SOUSA, Antonia Melo de. O custo aluno da educação infantil de Teresina: entre a realidade do Fundeb e o sonho do Caqi. Educação em Revista, Belo Horizonte, v.32, n. 1, p. 55-77, jan./mar. 2016. 
SÃO PAULO (Estado). Lei no 16.279 , de 8 de julho de 2016. Aprova o Plano Estadual de Educação de São Paulo e dá outras providências. Diário Oficial [do] Estado de São Paulo, São Paulo, 09 jul. 2016.

SANTA CATARINA (Estado). Lei no 16.794, de 14 de dezembro de 2015. Aprova o Plano Estadual de Educação (PEE) para o decênio 2015-2024 e estabelece outras providências. Diário Oficial [do] Estado de Santa Catarina, Florianópolis, 15 de dezembro de 2015.

SCHEINVAR, Estela; ALGEBAILE, Eveline. (Orgs.). Conselhos participativos e escola. Rio de Janeiro: DP\&A, 2005.

SENA, Paulo. A legislação do Fundeb. Cadernos de Pesquisa, São Paulo, v. 38, n. 134, p. 319-340, ago. 2008.

SERGIPE(Estado). Lei $\mathrm{n}^{\circ}$ 8.025, de 04 de setembro de 2015. Dispõe sobre o Plano Estadual de Educação - PEE, e dá providências correlatas. Diário Oficial [do] Estado de Sergipe, Aracajú, 8 set. 2015.

SOARES, Evanna. A publicação dos atos administrativos e das leis municipais na imprensa oficial à luz do princípio constitucional da publicidade. Revista Jus Navigandi, Teresina, v. 13, n. 1.982, 4 dez. 2008. Disponível em: <https://jus.com.br/artigos/12040>. Acesso em: 18 fev. 2016.

SOUZA, Donaldo Bello de. (Org.). Acompanhamento e controle social da educação: fundos e programas federais e seus conselhos locais. São Paulo: Xamã, 2006a.

(Org.). Conselhos municipais e controle social da educação: descentralização, participação e cidadania. São Paulo: Xamã, 2008.

(Org.). Mapa dos conselhos municipais de educação no Brasil: criação, implantação e funcionamento institucional e sociopolítico. São Paulo: Edições Loyola, 2013.

Conselhos de acompanhamento e controle social: tendências municipais. In:

(Org.). Acompanhamento e controle social da educação: fundos e programas federais e seus conselhos locais. São Paulo: Xamã, 2006b, p. 75-98.

SOUZA, Donaldo Bello de; DUARTE, Marisa Ribeiro Teixeira. Planos de educação no Brasil: projeções do sistema nacional de educação e suas variantes subnacionais. In: SOUZA, Donaldo Bello de; MARTINS, Ângela Maria (Orgs.). Planos de educação no Brasil: planejamentos, políticas, práticas. São Paulo: Loyola, 2014, p. 209-232.

SOUZA, Donaldo Bello de; MENEZES, Janaína Specht da Silva. Acompanhamento e avaliação dos/nos Planos Estaduais de Educação 2001-2010. Educação \& Realidade, Porto Alegre, v. 41, n. 2, p. 313-334, 2016.

Elaboração e aprovação de planos de educação no Brasil: do nacional ao local. Ensaio: Avaliação e Políticas Públicas em Educação, Rio de Janeiro, v. 23, n. 89, p. 901936, $2015 \mathrm{a}$.

Planos estaduais de educação: (des)vinculações com a gestão dos sistemas estaduais de ensino. In: SOUZA, Donaldo Bello de; DUARTE, Marisa Ribeiro Teixeira; OLIVEIRA, Rosimar de Fátima (Org.). Sistemas educacionais: concepções, tensões, desafios. São Paulo: Edições Loyola, 2015b, p. 139-172. 
SPINELLI, Maria Angélica dos Santos. Alimentação escolar: da centralização à descentralização. Campinas, 1998, 145 f. Tese (Doutorado em Saúde Coletiva) Universidade Estadual de Campinas, 1998.

TOCANTINS (Estado). Lei $\mathrm{n}^{\circ} 2.977$, de 8 de julho de 2015. Aprova o Plano Estadual de Educação do Tocantins - PEE/TO (2015-2025), e adota outras providências. Diário Oficial [do] Estado do Tocantins, Palmas, 9 jul. 2015.

VALLE, Bertha de Borja Reis do; VASCONCELOS, Maria Celi Chaves. (Orgs.). Conselhos municipais de educação: organização e atribuições nos sistemas de ensino do estado do Rio de Janeiro: Quartet; Faperj, 2012.

VASCONCELOS, Fábio. Falta controle no uso de fundo para o ensino: quase metade dos recursos do Fundeb é repassada para municípios que não cumprem exigências legais. $\mathbf{O}$ Globo, Rio de Janeiro, 31 de agosto de 2011, Caderno Rio, p. 19.

VENEZIANO, Alicia. Evolución del concepto de descentralización y algunas sugerencias para su abordaje. Revista Forum, Rio de Janeiro, n. 12, p. 1-8, 2002.

VIEIRA, Sofia Lerche; FARIAS, Isabel Maria Sabino de. Política educacional no Brasil: introdução histórica. Brasília, DF: Líber Livro, 2007.

WIEDERKEHR, Paulo Egon; AZEVEDO NETO, João Teobaldo de. Conselhos gestores de políticas públicas: Fundef/Fundeb. In: SOUZA, Donaldo Bello de. (Org.). Acompanhamento e controle social da educação: fundos e programas federais e seus conselhos locais. São Paulo: Xamã, 2006, p. 53-72.

\section{Notas}

\footnotetext{
${ }^{1}$ Professor Associado no Departamento de Políticas Públicas, Avaliação e Gestão da Educação (DEPAG) na Faculdade de Educação da Universidade do Estado do Rio de Janeiro (UERJ). Possui Pós-Doutorado em Política e Administração Educacional pela Faculdade de Psicologia e de Ciências da Educação (FPCE) da Universidade de Lisboa e Doutorado em Educação pela Universidade Federal do Rio de Janeiro (UFRJ). Email: donaldobello@gmail.com.

${ }^{2}$ De acordo com Soares (2008), é de competência do ente federado a definição da forma de publicidade dos atos editados, "Mas, conforme reconhecido pelo próprio Supremo Tribunal Federal, em decisão reportada por Meirelles [...], a publicação adequada para os atos da Administração deve ser feita no órgão oficial não valendo a veiculação somente na imprensa privada, no rádio ou na televisão, enfatizando o mesmo autor que devem ser compreendidos na expressão órgão oficial, além do Diário Oficial, 'os jornais contratados' pelas entidades públicas para efetivação das publicações oficiais [...]” [grifos no original].

${ }^{3}$ Disponível em: <http://pne.mec.gov.br/planos-de-educacao/situacao-dos-planos-de-educacao〉. Acesso em: 29 jul. 2016.

${ }^{4}$ Souza e Menezes (2016; 2015a, 2015b) e Souza e Duarte (2014) sinalizam que os estados do Rio de Janeiro e Minas Gerais foram aqueles que, no âmbito do PNE 2001-2010 (BRASIL, 2001), mais tardiamente tiveram os seus planos efetivamente transformados em lei, o primeiro, em 2009, enquanto que o segundo, em 2012, quando este próprio PNE não mais se encontrava em vigência.

${ }^{5}$ Cumpre esclarecer que, de acordo com o determinado no art. $1^{\circ}$ da Lei de Introdução ao Código Civil Brasileiro - Decreto-Lei ${ }^{\circ}$ 4.657, de 04 de setembro de 1942 (BRASIL, 1942), cuja ementa veio a ser alterada para "Lei de Introdução às Normas do Direito Brasileiro" pela Lei no 12.376, de 30 de dezembro de 2010 (BRASIL, 2010) - as leis somente entram em vigor depois de publicadas (SOARES, 2008).

${ }^{6}$ Em que pese à escassez de informações relativas ao primeiro grupo de PEEs anteriormente mencionado, é possível identificar no documento relativo ao Acre (2015) a ressalva de que o CEE se fez representar neste processo, embora a sua coordenação estivesse a cargo do Fórum Estadual de Educação (FEE). Já nos planos do Amazonas (2015) e do Paraná (2015) não constam referências a este tipo de atuação do CEE.
} 
${ }^{7}$ Para maiores informações sobre a composição, modo de distribuição e aplicação dos recursos do FUNDEF veja-se, por exemplo, Amaral (2012), Duarte e Faria (2010), Oliveira (2008), Davies (2001; 2000; 1999) e Callegari e Callegari (1997).

${ }^{8}$ Veja-se, também, Amaral (2012), Martins, P. (2011), Sena (2008) e Davies (2008).

${ }^{9} \mathrm{Na}$ visão de diversos autores, a lei atribuiu aos CACS do FUNDEF função relativamente complexa, que veio a demandar elevado preparo por parte de seus membros (AZEVEDO, 2002; DAVIES, 2003; 2001; MATOS, 2001), motivo pelo qual, para Davies (2003, p. 514), esses Conselhos vieram a ser "bastante inócuos, apesar de formalmente apresentarem um potencial para o controle social sobre o estado". Membros do próprio governo, em 2006, chega a reconhecer que a lei que regulamentou o FUNDEF "não criou mecanismos suficientes que fortalecessem sua atuação, tornando-os frágeis e vulneráveis" (WIEDERKEHR; AZEVEDO NETO, 2006, p. 63).

${ }^{10}$ O PNATE foi instituído por meio da Lei $n^{\circ} 10.880$, de 9 de junho de 2004, visando "oferecer transporte escolar aos alunos do Ensino Fundamental público, residentes em área rural, por meio de assistência financeira, em caráter suplementar, aos Estados, Distrito Federal e Municípios [...]” (BRASIL, 2004, art. $2^{\circ}$ ). Veja-se também Ribeiro e Jesus (2015) e Rangel (2006).

${ }^{11}$ O Programa de Apoio aos Sistemas de Ensino para Atendimento à Educação de Jovens e Adultos, também instituído pela Lei $\mathrm{n}^{\circ} 10.880 / 2004$, objetiva “ampliar a oferta de vagas na educação fundamental pública de jovens e adultos, em cursos presenciais com avaliação no processo, por meio de assistência financeira, em caráter suplementar, aos sistemas de ensino estaduais, municipais e do Distrito Federal" (BRASIL, 2004, art. $\left.3^{\circ}\right)$.

12 A ocupação da presidência dos CACS do FUNDEF por representantes do governo contribuiu, em larga medida, para a inoperância institucional e sociopolítica desses conselhos, isto em função dos vínculos de subordinação que daí foram estabelecidos em relação aos conselheiros, minorando a autonomia deste órgão colegiado (AZEVEDO, 2002; MATOS, 2001; GOMES; PASCOALINO, 2000).

${ }^{13}$ Resultados de avaliações mais recentes sobre alguns CACS do FUNDEB no País podem ser encontrados, por exemplo, no estudo de Conceição e Fialho (2014) e, ainda de Braga (2011).

${ }^{14}$ Nos seus dez anos de implantação (1997-2006), o FUNDEF operou sob uma série de irregularidades, a exemplo da denúncia realizada pelo Ministério Público Federal (MPF), em 2004, na qual se constatou que cerca de $75 \%$ desses recursos foram, à época, desviados, o que levou este órgão, em conjunto com a Controladoria Geral do União (CGU), a afirmar que "ao lado das salas de aula, em todo o país, há uma antisala do crime" (CASTILHO; SOUZA, 2004, p. 42).

15 Sobre o desempenho mais recente do FUNDEB e seus impactos no financiamento da educação pública vejam-se, entre outros, Sales e Sousa (2016), Pinto (2014), Fernandes e Fernandes (2014), Gouveia e Silva (2012), Pinto e Alves (2011) e Campos e Cruz (2009).

${ }^{16}$ Disponível em: <http://www.fnde.gov.br/programas/alimentacao-escolar/alimentacao-escolarapresentacao>. Acesso em: 5 mar. 2016.

17 Importante destacar que, a par dos estudos que vêm identificando sérios óbices ao funcionamento desses conselhos, alguns outros trabalhos, como o de Gabriel et al. (2013, p. 971), pautado na avaliação de CACS municipais do PNAE no Estado de Santa Catarina, constata que "A maioria dos conselhos analisava a prestação de contas, fiscalizava os recursos, zelava pela qualidade do PNAE em todos os níveis, orientava o armazenamento dos alimentos, participava da elaboração do cardápio, acompanhava a compra de gêneros e tinha regimento interno".

18 Disponível em: <http://g1.globo.com/jornal-nacional/noticia/2016/02/mp-sp-investiga-esquema-de-desviode-dinheiro-da-merenda-escolar.html>. Acesso em: 18 mar. 2016.

${ }^{19}$ No caso do plano do Acre, tal disposição chega a ser elevada à condição de artigo da lei que regulamenta o PEE, nos termos de que "São diretrizes do Plano Estadual de Educação: VI - promoção da gestão democrática, ampliando a participação das famílias, profissionais da educação e da sociedade, na organização, definição, execução, acompanhamento e controle das políticas públicas de educação" (ACRE, 2015, art. $2^{\circ}$ ).

${ }^{20}$ No PNE 2001-2010, as referências ao CACS remetem ao FUNDEF, que vigorou no período 1996-2006 (BRASIL, 1997), estando associadas, no Eixo Temático V (Financiamento e Gestão): à visibilidade e identificação de desvios dos recursos de competência deste Fundo; à importância do seu fortalecimento como órgão de gestão nos sistemas de ensino e à fiscalização necessária para o cumprimento de determinadas metas de financiamento do próprio plano. Seu valor para este plano torna-se ainda mais evidente quanto, de um lado, é evocado como órgão a ser constituído para o acompanhamento e controle social, em todos os níveis, dos "recursos destinados à Educação não incluídos no FUNDEF, qualquer que seja sua origem" (BRASIL, 2001a, 11.3.2 Objetivos e Metas / Gestão), nos moldes desses mesmos 
conselhos, e, de outro, no Eixo Temático VI (Acompanhamento e Avaliação), na condição de instância coresponsável para a boa condução do plano (BRASIL, 2001a).

21 "Meta 19: assegurar condições, no prazo de 2 (dois) anos, para a efetivação da gestão democrática da educação, associada a critérios técnicos de mérito e desempenho e à consulta pública à comunidade escolar, no âmbito das escolas públicas, prevendo recursos e apoio técnico da União para tanto" (BRASIL, 2014).

${ }^{22}$ Segundo Bordignon (2014, p. 32), “As estratégias definem a utilização dos recursos, os meios e processos para realizar a caminhada rumo ao alcance dos objetivos, a realização das metas. Em última análise as estratégias devem constituir programas definidores das ações do governo para alcançar as metas. $\mathrm{O}$ termo estratégia, do grego stratègós, significa a arte do general, ou seja: a arte de comando, de liderança da ação, de utilizar os recursos e as condições favoráveis disponíveis para avançar rumo às metas [grifos no original]".

${ }^{23}$ Com relação ao PEE do Maranhão, conforme anteriormente assinalado, embora não tenha previsto a ampliação dos programas de apoio e formação dos conselheiros atuantes nos CACS, tampouco explicitado apoio financeiro e logístico a estes conselhos, curiosamente, propõe a criação de uma "casa dos conselhos de educação ou similar com representantes dos conselhos das escolas públicas e de conselhos de outras políticas públicas relacionadas com a educação para a socialização de informações e a descentralização das tomadas de decisão a respeito da Educação Básica, contribuindo assim, para o fortalecimento do controle social". (MARANHÃO, 2014, Estratégia 20.4).

24 "Meta 20: ampliar o investimento público em educação pública de forma a atingir, no mínimo, o patamar de $7 \%$ (sete por cento) do Produto Interno Bruto - PIB do País no 5ำ (quinto) ano de vigência desta Lei e, no mínimo, o equivalente a 10\% (dez por cento) do PIB ao final do decênio" (BRASIL, 2014).

${ }^{25}$ Importante destacar que o PEE de Rondônia (2015) distribui as suas 20 metas a partir de 13 eixos temáticos básicos, expondo estrutura similar ao do PNE 2011-2010 (BRASIL, 2001), motivo pelo qual a numeração das estratégias é precedida pelo índice correspondente ao eixo ao qual uma determinada meta pertença.

Recebido: $\quad$ março-16 Aprovado: setembro-16 